\title{
Marine turtles are not sexually size dimorphic, a pattern that is distinct from non-marine aquatic turtles
}

\author{
Christine Figgener ${ }^{1}$, Joseph Bernardo ${ }^{1}$, and Pamela Plotkin ${ }^{2}$ \\ ${ }^{1}$ Texas A\&M University College Station \\ ${ }^{2}$ Texas A\&M University
}

May 5, 2020

\begin{abstract}
Turtles have been prominent subjects of analyses of sexual size dimorphism (SSD) owing to their mating system and habitat diversity. In prior studies, marine turtles were grouped with non-marine aquatic turtles (NMAT). This is odd because it is well-established that the marine environment imposes a distinct selective milieu on body form of vagile vertebrates, driven by convergent adaptations for energy-efficient propulsion and drag reduction. We generated a comprehensive database of adult marine turtle body size (38,569 observations across all species), which we then used to evaluate both the magnitude of SSD in marine turtles and how it compares to SSD in NMAT. We find that marine turtles are not sexually size dimorphic, whereas NMAT typically exhibit female-biased SSD. We argue that the reason for this difference is the sustained long-distance swimming that characterises marine turtle ecology, which entails significant energetic costs incurred by both sexes. Hence, the ability of either sex to allocate proportionately more to growth than the other is likely constrained, meaning that sexual differences in growth and resultant body size are not possible. Consequently, lumping marine turtles with NMAT dilutes the statistical signature of different kinds of selection on SSD and should be avoided in future studies.
\end{abstract}

\section{Background}

Sexual size dimorphism (SSD) is a phenomenon that has received a great deal of theoretical and empirical attention, as it is thought to reflect variation in sex-specific selection due to ecological performance, and fitness effects arising from fecundity selection and mating systems (D J Fairbairn, 1997; Daphne J Fairbairn, Blanckenhorn, \& Székely, 2007; Shine, 1989, 1990). Turtles (Order Testudines) have been prominent model systems for comparative analyses aimed at understanding the causes of SSD, owing to the diversity of their mating systems, habitats (freshwater, terrestrial, marine) they occupy, and the wide availability of data on body size of many species (Agha et al., 2018; Berry \& Shine, 1980; Ceballos, Adams, Iverson, \& Valenzuela, 2013; Gibbons \& Lovich, 1990; Gosnell, Rivera, \& Blob, 2009; Halámková, Schulte, \& Langen, 2013; Regis \& Meik, 2017). All of these analyses assign turtle species to different habitat types (aquatic, semi-aquatic, terrestrial, etc.), but with varying degrees of detail. In all cases, marine turtles, the subject of this paper, are lumped with non-marine aquatic turtles (NMAT).

The seven species of marine turtles comprise a monophyletic lineage (superfamily Chelonioidea) containing two families (Cheloniidae, Dermochelyidae) (reviewed in Figgener, Bernardo, and Plotkin (2019)). Both extant and extinct marine turtles are well-known to exhibit striking adaptations to the marine environment including forelimbs highly modified into flippers with concomitant neuromuscular repatterning, and streamlining of body form as is seen in other highly vagile marine vertebrates (Frank E Fish, 1993; Kelley \& Pyenson, 2015; Pyenson, Kelley, \& Parham, 2014). Three issues pertaining to the marine turtle data that have been used in prior analyses of testudine SSD prompted this study. The first issue is that most reviews do not include data for all seven species, (two to five species have been included) although data exist for all seven species in the literature. Second, most studies include species' mean values that are often based 
on a single population ignoring a large amount of literature data on body sizes in different populations. Further, some studies report values whose origin in the primary literature is unclear (Supplementary Table 1). Because most marine turtles occupy far more expansive geographic ranges (Figgener et al., 2019) than any other turtle species including both temperate and tropical regions, intraspecific diversity in body size may influence overall conclusions about SSD in marine turtles. The third and possibly most concerning issue is that all the prior analyses cited above are consistent in grouping marine turtles with other aquatic turtles despite their well-known distinct morphology and ecology, which includes long-distance, often trans-oceanic migrations (Godley et al., 2008; Graeme C. Hays \& Hawkes, 2018; Plotkin, 2003, 2010).

In this paper, we critically examine these issues. First, we address the lack of SSD data for marine turtles in previous studies by assembling the most comprehensive dataset to date on body size of all seven marine turtle species, including estimates from multiple populations. We then analysed these data to describe quantitatively intraspecific and interspecific patterns in marine turtle SSD. Finally, we compared these new estimates of marine turtle SSD to data from other fully aquatic turtles to test the hypothesis that the previous grouping of marine turtles with other aquatic turtles in comparative analyses of sexual size dimorphism is justified.

Methods

We carefully reviewed all data on marine turtle body size reported and used in prior analyses of testudine SSD to validate their accuracy and to gauge any omissions. As part of this process, we re-examined all the primary sources reported in these studies. This exercise revealed many omissions and errors (summarised in Supplementary Table 1). Therefore, we generated a novel, comprehensive dataset (Supplementary Table 2) of sex-specific body sizes (carapace length, CL) of adult marine turtles in which data for both sexes were reported from the same population using data from primary sources. The detailed methodology and the resultant dataset for this synthesis are detailed in the Electronic Supplementary Material.

We analysed this new dataset to test the hypothesis that marine turtles exhibit significant sexual size dimorphism. First, to gain an overview of species differences as well as intraspecific variation, we computed sex-specific mean values for each population and species. Then we plotted male vs female size for each population and computed a regression of males versus females (Ranta, Laurila, \& Elmberg, 1994). The null hypothesis, in this case, is that males and females for a given species do not differ in size, which implies a slope of one and an intercept of zero. This null hypothesis thus differs from the standard null in regressions that both the slope and intercept are zero. Because the data were unbalanced with respect to the number of populations per species (Fig. 1A), we repeated the analysis using only mean values for each species. In both models, each component of the null hypothesis (slope, intercept) was evaluated using a one sample, two-tailed t-test.

\section{Comparison of SSD of marine to non-marine aquatic turtles}

Data for NMAT were derived from published summaries in two recent analyses of sexual dimorphism in turtles (Agha et al., 2018; Regis \& Meik, 2017). Only sex-specific mean body size data were available in these studies. We aggregated data from the two most comprehensive studies and updated the taxonomic assignments of the studied populations. Additional details of this process and the resultant dataset (Supplementary Table S3) are provided in the Electronic Supplementary Material.

We used two approaches to test the hypothesis that marine and NMAT should be considered as a single group (aquatic turtles) in analyses of SSD as has been assumed in previous analyses of turtle SSD (Agha et al., 2018; Berry \& Shine, 1980; Ceballos et al., 2013; Gosnell et al., 2009). First, we plotted male versus female mean body size for each species of both non-marine and marine turtles and fit separate regressions for the two groups. We then computed an ANOVA in which we included habitat (marine vs non-marine) as a classification variable. Because there is a correlation between habitat and overall body size (average sizes of marine turtles are far greater than those of NMAT), we might wrongly ascribe to 'habitat' a difference driven simply by average size. Therefore, we also included an interaction term between female CL and habitat to account for this association. 
Second, we computed the Lovich-Gibbons Sexual Dimorphism Index $\left(\mathrm{SDI}_{\mathrm{LG}}\right)$ (Lovich \& Gibbons, 1992) as modified by D J Fairbairn (1997), hereafter $\mathrm{SDI}_{\mathrm{LGF}}$, for all species:

$\mathrm{SDI}_{\mathrm{LGF}}=\frac{\text { mean size of largest sex }}{\text { mean size of smallest sex }}-1$

with positive values (arbitrarily) indicating female-biased SSD, 0 indicating no SSD, and negative values (arbitrarily) indicating male-biased SSD. We plotted these for visual comparison, but we also computed the

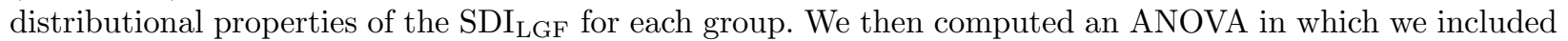
habitat (marine vs non-marine) as a classification variable. All model effects are interpreted using the Type III Sums of Squares.

\section{RESULTS}

We obtained reliable body size data for 36 populations representing all seven species of marine turtles, with a total sample size of 38,569 individuals (36,761 females; 1,808 males), the most comprehensive dataset of marine turtle body size to date (Supplementary Table S2). By comparison, prior analyses of SSD in turtles (Agha et al., 2018; Berry \& Shine, 1980; Ceballos et al., 2013; Gibbons \& Lovich, 1990; Gosnell et al., 2009; Halámková et al., 2013; Regis \& Meik, 2017) included data for only two to five marine turtle species, and often each species was represented by a single population (See Supplementary Table S1 for details).

SSD in marine turtles

Availability of body sizes for both sexes within a single population varied widely among the seven species of marine turtles (Supplementary Table S2). By far the most data were available for the green turtle (Chelonia mydas ), which yielded credible estimates from 18 studies (Fig. 1A), with six populations for the loggerhead (Caretta caretta), four populations for the olive ridley (Lepidochelys olivacea), three populations for the hawksbill (Eretmochelys imbricata), two populations for the leatherback (Dermochelys coriacea), and two studies for the Kemp's ridley (Lepidochelys kempii), and a single population of the flatback (Natator depressus ). The sex-specific means and samples sizes are shown in Figure 1B and summarised in Supplementary Table S2. For the species for which we have estimates from five or more populations (C. mydas, C. caretta ), it is noteworthy that the degree and direction of SSD varies.

Figure 1A also illustrates the regression of sex-specific mean values (male vs female) for all populations. Neither the slope nor the intercept of this regression differed significantly from the null expectation (slope: $\mathrm{t}(33)=0.052, \mathrm{t}_{\text {crit }}=2.034, \mathrm{p}=1$; intercept: $\left.\mathrm{t}(33)=-0.514, \mathrm{t}_{\text {crit }}=2.034, \mathrm{p}=0.611\right)$. The upper $95 \%$ confidence interval of the regression is slightly below the 1:1 line, indicating a weak female-biased SSD. Examination of the scatter suggests that this overall pattern is driven largely by $C$. mydas .

Comparisons of SSD in marine with non-marine aquatic turtles

Regression Approach .- Figure 2 illustrates separate regressions of male versus female body size for marine and NMAT with 95\% confidence intervals and the 1:1 line (null hypothesis) for comparison. The regression for marine turtles using only the species-mean data (Fig. 2A) was: male CL $=-2.4647+1.0014$ (female CL) adj $\mathrm{r}^{2}=0.99, \mathrm{p}<0.0001$ ). Neither the slope nor the intercept differed significantly from the null expectation (slope: $\mathrm{t}(4)=-0.001, \mathrm{t}_{\text {crit }}=2.267, \mathrm{p}=0.99$; intercept: $\left.\mathrm{t}(4)=-1.874, \mathrm{t}_{\text {crit }}=2.267, \mathrm{p}=1\right)$. The $95 \%$ confidence intervals of this regression overlap or encompasses the 1:1 line.

By contrast, NMAT exhibit a wide range of departures from equality in size, mostly in the direction of larger female size (Fig. 2A), which is reflected by a slope of 0.76 . The $95 \%$ confidence intervals overlap the 1:1 line only in the domain of the very smallest species $(<\sim 15 \mathrm{~cm}$ CL). The ANOVA (Table 1a) indicated an overall significant effect of female size on male size, but also a significant interaction between female size and habitat, indicating that this effect differed between marine and non-marine habitats. In other words, in conjunction with the results of the regressions, this means that females are on average larger than males in NMAT, but sexes do not differ in size in marine turtles.

$S D I_{L G F}$ Approach .- Figure 2B illustrates $\mathrm{SDI}_{\mathrm{LGF}}$ values for all 94 species of aquatic turtles (87 non-marine, seven marine). The values for marine turtles are very close to or overlapping the null expectation of no sexual 
size dimorphism $\left(\mathrm{SDI}_{\mathrm{LGF}}=0\right)$. The mean $\mathrm{SDI}_{\mathrm{LGF}}$ for marine turtles was $0.027 \pm 0.0103$, and ranged from 0.002 to 0.067 , whereas the mean $\mathrm{SDI}_{\mathrm{LGF}}$ for NMAT was an order of magnitude higher and biased towards females $(0.337 \pm 0.0419$, range -0.215 to 1.684$)$. ANOVA (Table $1 \mathrm{~b})$ indicated that these distributions were significantly different $\left(\mathrm{F}_{1,92}=4.339, \mathrm{p}=0.04\right)$. Furthermore, the range of values was considerably larger in non-marine turtles (1.899) than in marine species (0.066).

\section{DISCUSSION}

Our comprehensive review of the literature permitted the first definitive statistical evaluation of the degree of SSD in marine turtles, reflecting information from all seven extant species. Our analysis revealed a striking lack of SSD (Fig. 1), a pattern that is notably distinct from NMAT, which typically exhibit female-biased SSD (Fig. 2). Female-biased SSD is typically interpreted as a response to fecundity selection, in the absence of male combat, which should result in larger male size via sexual selection (Berry \& Shine, 1980). Marine turtles do not exhibit male combat and therefore would be expected to exhibit female-biased SSD, with all other conditions remaining the same. Whatever the sources of selection, differences between sexes in body size arise due to differences in growth rates over the same prematuration interval or due to differences in the prematuration duration of growth (Bernardo, 1993; Cox \& John-Alder, 2007; J. Stamps \& Krishnan, 1997; J. A. Stamps, 2008). A third possibility is differential, size-specific mortality that influences one sex more than the other(DeGregorio, Grosse, \& Gibbons, 2012; Roosenburg, 1991). The lack of SSD in marine turtles thus requires an understanding of what kind of selection is prohibiting differentiation in size between sexes. We suggest that this is due to both the high energetic cost of locomotion in the marine environment coupled with frequent long-distance movements by both sexes.

It is well-established that the marine environment imposes strong selection on body form of large, widelyforaging vertebrates (Frank E Fish, 1993, 1998; Frank E. Fish, Howle, \& Murray, 2008; Kelley \& Pyenson, 2015; Seibel \& Drazen, 2007; Webb, 1988; Webb \& De Buffrénil, 1990; Williams Terrie, 1999), driven principally by selection for drag reduction and therefore cost-efficient swimming (Frank E Fish, 1993, 1998; Webb, 1988; Williams Terrie, 1999). Saltwater is denser and has both higher dynamic and kinematic viscosities than freshwater (Vogel, 1994). Consequently, we would expect from first principles that the marine environment establishes a different selective milieu on sexual dimorphism.

Marine turtles are morphologically distinctive among all aquatic turtles in several ways. First, marine turtle limbs reflect strong selection for specialised locomotion, both in form and in function. While all limbs are modified into flippers, the forelimbs are hypertrophied and modified into broad, distally tapered, rigid, winglike flippers (Davenport, Munks, \& Oxford, 1984; Renous, de Broin, Depecker, Davenport, \& Bels, 2007; Wyneken, 1997). Apart from the external wing-like shape itself, the underlying bony architecture is distinct in marine turtles (Renous et al., 2007). In particular, the humerus is flattened compared to other turtles (Renous et al., 2007; Wyneken, 1997) and biomechanical analyses indicate that this confers great strength and hydrodynamic efficiency (Dickson \& Pierce, 2019). The locomotory pattern of marine turtles consists of a synchronous upward/downward sweeping motion of the fore flippers that generates thrust (Davenport et al., 1984; Wyneken, 1997), similar to the pattern in other marine tetrapods that have flippers (Clark \& Bemis, 1979; Walker, 2002). That such derived flippers have convergently evolved across multiple lineages of other marine tetrapods, including seals, penguins, and plesiosaurs (Wyneken, 1997), indicates strong selection for efficient long-distance swimming. It is well established from mathematical modelling that flapping appendages in large aquatic animals permit efficient and rapid propulsion (Blake, 1981; Walker, 2002; Walker \& Westneat, 2000).

The second morphological specialisation of marine turtles is the extraordinary streamlining of their body form (Davenport et al., 1984; Wyneken, 1997). This stereotypic streamlining is evident throughout their evolutionary history including the oldest known definitive species, Desmatochelys padillai (Cadena \& Parham, 2015), and across an order of magnitude range in body size from the smallest living species Lepidochelys kempii ( $\sim 63 \mathrm{~cm}$ carapace length) to the largest known species, the extinctArchelon ischyros (Wieland, 1896), which exceeded $400 \mathrm{~cm}$ in carapace length. A further adaptation evident in $D$. coriacea are the longitudinal dorsal ridges on the carapace that enhance hydrodynamic performance (Bang, Kim, Lee, \& Choi, 2016). 
Taken together, these specialisations indicate that selection has optimised marine turtle morphology for energetically efficient swimming. Indeed, a key feature of marine turtle biology is their capacity to exploit resources across vast geographic expanses. Both sexes of all seven species of marine turtles undertake longdistance, sometimes trans-oceanic migrations covering many hundreds to thousands of kilometers (Boyle et al., 2009; Graeme C Hays, Houghton, \& Myers, 2004; Graeme C. Hays, Mortimer, Ierodiaconou, \& Esteban, 2014; Graeme C. Hays \& Scott, 2013; Luschi, Hays, \& Papi, 2003; Plotkin, 2003, 2010; Shillinger et al., 2008). Two species (D. coriacea and L. olivacea) are oceanic, pelagic, widely-foraging predators (Graeme C Hays et al., 2004; Plotkin, 2010; Shillinger et al., 2008). Satellite tagging studies show that D. coriacea achieves a mean speed of 33-49 km/d, with a maximum of $62 \mathrm{~km} / \mathrm{d}$ (Shillinger et al., 2008) and L. olivacea a mean of $28.32 \mathrm{~km} / \mathrm{d}$ and a maximum of $79.4 \mathrm{~km} / \mathrm{d}$ (Plotkin, 2010).

Despite their having evolved unique morphology among turtles for efficient swimming, this high vagility lifestyle still entails substantial energetic expenditure. Unfortunately, few quantitative data on the energetic requirements of swimming in adult marine turtles are available. However, Prange (1976) studied the metabolic cost of swimming in juvenile Chelonia mydas . By extrapolating these costs, he estimated that the energetic demand for a long-distance migration of adults between breeding and feeding grounds would require approximately $21 \%$ of their body mass in fat stores. Given the common body form and long-distance movement of all marine turtle species, it is not far-fetched that these energy requirements are incurred by all of the species.

Because the high energetic costs of sustained swimming are incurred by both sexes, neither sex can allocate significant energy to continued growth after maturation and therefore neither sex can achieve a larger size than the other (Bernardo, 1993; Cox \& John-Alder, 2007; J. Stamps \& Krishnan, 1997; J. A. Stamps, 2008). For instance, female-biased SSD is usually attributed to fecundity selection, but the ability for female marine turtles to allocate energy to enhanced post-maturation growth in response to fecundity selection appears to be prohibited by their costly locomotion. An analysis of growth rates in different populations of loggerhead turtles instantiates that the cost of achieving larger size comes at the expense of reproductive frequency (Hatase \& Tsukamoto, 2008). Thus, the capacity to continue to grow and produce eggs come into close conflict because of the energetic background costs of locomotion (Hatase \& Tsukamoto, 2008). A further indication that marine turtles lack discretionary energy for continued growth that could produce SSD is found in their unusual post-maturation growth patterns. Marine turtles exhibit determinate-like growth (Omeyer, Fuller, Godley, Snape, \& Broderick, 2018), a pattern which is unlike other turtles (Congdon, Gibbons, Brooks, Rollinson, \& Tsaliagos, 2013; Gibbons, Semlitsch, Greene, \& Schubauer, 1981; Lindeman, 1999) and in fact unlike most other ectotherms (Bernardo, 1993; Gotthard, 2001; Sebens, 1987; Tilley, 1980) which exhibit indeterminate growth.

In conclusion, our study demonstrated that, unlike NMAT, marine turtles are not sexually size dimorphic, and we argued that this difference is due to the distinct selective milieu imposed by the oceanic environment. Hence, future studies should acknowledge this distinction and no longer group marine turtles with NMAT as numerous studies have previously done. We also note that, where data are available for multiple populations of the same species (Figure 1A), the magnitude and direction of SSD vary. This indicates that the common practise of basing a species-level trait estimate on a single population likely introduces error variance in comparative datasets. Further, we note that in our comprehensive dataset, the sample size for females was more than 20 times that for males, and in the case of $N$. depressus, only a single male has been measured. This unbalanced sample size between sexes is likely due to the oversampling of nesting fmales; future studies need to be deliberate about acquiring male data on marine turtle males.

\section{Literature Cited}

Agha, M., Ennen, J. R., Nowakowski, A. J., Lovich, J. E., Sweat, S. C., \& Todd, B. D. (2018). Macroecological patterns of sexual size dimorphism in turtles of the world. Journal of Evolutionary Biology, 31 (3), 336-345. doi:10.1111/jeb.13223

Bang, K., Kim, J., Lee, S.-I., \& Choi, H. (2016). Hydrodynamic role of longitudinal dor- 
sal ridges in a leatherback turtle swimming.Scientific Reports, 6 , 34283. doi:10.1038/srep34283 https://www.nature.com/articles/srep34283\#supplementary-information

Bernardo, J. (1993). Determinants of maturation in animals. Trends in Ecology \& Evolution, 8 (5), 166-173. doi:https://doi.org/10.1016/0169-5347(93)90142-C

Berry, J. F., \& Shine, R. (1980). Sexual size dimorphism and sexual selection in turtles (Order Testudines). Oecologia, 44 , 185-191.

Blake, R. (1981). Mechanics of drag-based mechanisms of propulsion in aquatic vertebrates. Paper presented at the Symposium of the Zoological Society London.

Boyle, M. C., FitzSimmons, N. N., Limpus, C. J., Kelez, S., Velez-Zuazo, X., \& Waycott, M. (2009). Evidence for transoceanic migrations by loggerhead sea turtles in the southern Pacific Ocean. Proceedings of the Royal Society B: Biological Sciences, 276 (1664), 1993-1999. doi:10.1098/rspb.2008.1931

Cadena, E. A., \& Parham, J. F. (2015). Oldest known marine turtle? A new protostegid from the Lower Cretaceous of Colombia. PaleoBios, 32 , 1-42.

Ceballos, C. P., Adams, D. C., Iverson, J. B., \& Valenzuela, N. (2013). Phylogenetic patterns of sexual size dimorphism in turtles and their implications for Rensch's rule. Evolutionary Biology, 40 (2), 194-208. doi:10.1007/s11692-012-9199-y

Clark, B. D., \& Bemis, W. (1979). Kinematics of swimming of penguins at the Detroit Zoo. Journal of Zoology, 188 (3), 411-428. doi:10.1111/j.1469-7998.1979.tb03424.x

Congdon, J. D., Gibbons, J. W., Brooks, R. J., Rollinson, N., \& Tsaliagos, R. N. (2013). Indeterminate growth in long-lived freshwater turtles as a component of individual fitness. Evolutionary Ecology, 27 (2), 445-459. doi:10.1007/s10682-012-9595-x

Cox, R. M., \& John-Alder, H. B. (2007). Growing apart together: the development of contrasting sexual size dimorphisms in sympatricSceloporus lizards. Herpetologica, 63 (3), 245-257. doi:10.1655/00180831(2007)63[245:GATTDO]2.0.CO;2

Davenport, J., Munks, S. A., \& Oxford, P. J. (1984). A comparison of the swimming of marine and freshwater turtles. Proceedings of the Royal Society B: Biological Sciences, 220 (1221), 447-475. doi:10.1098/rspb.1984.0013

DeGregorio, B. A., Grosse, A. M., \& Gibbons, J. W. (2012). Density and size class distribution of yellowbellied sliders ( Trachemys scripta scripta ) inhabiting two barrier island wetlands. Herpetological Conservation and Biology, 7 (3), 306-312.

Dickson, B. V., \& Pierce, S. E. (2019). Functional performance of turtle humerus shape across an ecological adaptive landscape.Evolution, 73 (6), 1265-1277. doi:10.1111/evo.13747

Fairbairn, D. J. (1997). Allometry for sexual size dimorphism: pattern and process in the coevolution of body size in males and females. Annual review of ecology and systematics, 28 , 659-687.

Fairbairn, D. J., Blanckenhorn, W. U., \& Székely, T. (2007). Sex, Size and Gender Roles: Evolutionary Studies of Sexual Size Dimorphism . Oxford: Oxford University Press.

Figgener, C., Bernardo, J., \& Plotkin, P. T. (2019). Beyond trophic morphology: stable isotopes reveal ubiquitous versatility in marine turtle trophic ecology. Biological Reviews, 0 (0). doi:10.1111/brv.12543

Fish, F. E. (1993). Influence of hydrodynamic-design and propulsive mode on mammalian swimming energetics. Australian Journal of Zoology, 42 (1), 79-101. doi:https://doi.org/10.1071/ZO9940079

Fish, F. E. (1998). Imaginative solutions by marine organisms for drag reduction. Paper presented at the International Symposium on Seawater Drag Reduction, Newport, R. 
Fish, F. E., Howle, L. E., \& Murray, M. M. (2008). Hydrodynamic flow control in marine mammals. Integrative and Comparative Biology, 48 (6), 788-800. doi:10.1093/icb/icn029

Gibbons, J. W., \& Lovich, J. E. (1990). Sexual dimorphism in turtles with emphasis on the slider turtle (Trachemys scripta).Herpetological Monographs, 4 , 1-29.

Gibbons, J. W., Semlitsch, R. D., Greene, J. L., \& Schubauer, J. P. (1981). Variation in age and size at maturity of the slider turtle (Pseudemys scripta). The American Naturalist, 117 (5), 841-845.

Godley, B. J., Blumenthal, J. M., Broderick, A. C., Coyne, M. S., Godfrey, M. H., \& Hawkes, L. A. (2008). Satellite tracking of sea turtles: where have we been and where do we go next? Endangered Species Research, 4 , 3-22. doi:10.3354/esr00060

Gosnell, S. J., Rivera, G., \& Blob, R. W. (2009). A phylogenetic analysis of sexual size dimorphism in turtles. Herpetologica, 65 (1), 70-81. doi:10.1655/07-057r2.1

Gotthard, K. (2001). Growth strategies of ectothermic animals in temperate environments. In D. Atkinson \& M. Thorndyke (Eds.),Environment and Animal Developmental: Genes, Life Histories and Plasticity (pp. 287-304). Oxford: BIOS Scientifc Publishers Ltd.

Halámková, L., Schulte, I. I. J. A., \& Langen, T. A. (2013). Patterns of sexual size dimorphism in Chelonia . Biological Journal of the Linnean Society, 108 (2), 396-413. doi:10.1111/j.1095-8312.2012.02015.x

Hatase, H., \& Tsukamoto, K. (2008). Smaller longer, larger shorter: energy budget calculations explain intrapopulation variation in remigration intervals for loggerhead sea turtles (Caretta caretta). Canadian Journal of Zoology, 86 (7), 595-600. doi:10.1139/Z08-035

Hays, G. C., \& Hawkes, L. A. (2018). Satellite tracking sea turtles: opportunities and challenges to address key questions. Frontiers in Marine Science, 5 , 432. doi:10.3389/fmars.2018.00432

Hays, G. C., Houghton, J. D. R., \& Myers, A. E. (2004). Endangered species: Pan-Atlantic leatherback turtle movements. Nature, 429 (6991), 522. doi:10.1038/429522a

Hays, G. C., Mortimer, J. A., Ierodiaconou, D., \& Esteban, N. (2014). Use of long-distance migration patterns of an endangered species to inform conservation planning for the world's largest marine protected area. Conservation Biology, 28 (6), 1636-1644. doi:10.1111/cobi.12325

Hays, G. C., \& Scott, R. (2013). Global patterns for upper ceilings on migration distance in sea turtles and comparisons with fish, birds and mammals. Functional Ecology, 27 (3), 748-756. doi:10.1111/1365-2435.12073

Kelley, N. P., \& Pyenson, N. D. (2015). Evolutionary innovation and ecology in marine tetrapods from the Triassic to the Anthropocene.Science, 348 (6232), aaa3716. doi:10.1126/science.aaa3716

Lindeman, P. V. (1999). Growth curves for Graptemys, with a comparison to other Emydid turtles. The American Midland Naturalist, 142 (1), 141-151, 111.

Lovich, J. E., \& Gibbons, J. W. (1992). A review of techniques for quantifying sexual size dimorphism. Growth, Development, and Aging, 56 (4), 269-281.

Luschi, P., Hays, G. C., \& Papi, F. (2003). A review of long-distance movements by marine turtles, and the possible role of ocean currents.Oikos, 103 (2), 293-302. doi:10.1034/j.1600-0706.2003.12123.x

Omeyer, L. C. M., Fuller, W. J., Godley, B. J., Snape, R. T. E., \& Broderick, A. C. (2018). Determinate or indeterminate growth? Revisiting the growth strategy of sea turtles. Marine Ecology Progress Series, 596 , 199-211.

Plotkin, P. T. (2003). Adult migrations and habitat use. In P. L. Lutz, J. A. Musick, \& J. Wyneken (Eds.), The biology of sea turtles(Vol. II, pp. 225-241). Boca Raton, FL: CRC Press. 
Plotkin, P. T. (2010). Nomadic behaviour of the highly migratory olive ridley sea turtle Lepidochelys olivacea in the Eastern Tropical Pacific Ocean. Endangered Species Research, 13 (1), 33-40. doi:10.3354/esr00314

Prange, H. D. (1976). Energetics of swimming of a sea turtle. The Journal of Experimental Biology, 64 (1), 1.

Pyenson, N. D., Kelley, N. P., \& Parham, J. F. (2014). Marine tetrapod macroevolution: physical and biological drivers on $250 \mathrm{Ma}$ of invasions and evolution in ocean ecosystems. Palaeogeography, Palaeoclimatology, Palaeoecology, 400 , 1-8.

Ranta, E., Laurila, A., \& Elmberg, J. (1994). Reinventing the wheel: analysis of sexual dimorphism in body size. Oikos, 70 (3), 313-321. doi:10.2307/3545768

Regis, K. W., \& Meik, J. M. (2017). Allometry of sexual size dimorphism in turtles: a comparison of mass and length data. PeerJ, 5 , e2914. doi:10.7717/peerj.2914

Renous, S., de Broin, F. d. L., Depecker, M., Davenport, J., \& Bels, V. (2007). Evolution of locomotion in aquatic turtles. In J. Wyneken, M. H. Godfrey, \& V. Bels (Eds.), Biology of Turtles (pp. 111-152). Boca Raton, FL: CRC Press.

Roosenburg, W. M. (1991). The diamondback terrapin: population dynamics, habitat requirements, and opportunities for conservation.Paper presented at the New Perspectives in the Chesapeake System: A Research and Management Partnership., Baltimore, MD.

Sebens, K. P. (1987). The ecology of indeterminate growth in animals. Annual review of ecology and systematics, 18 , 371-407.

Seibel, B. A., \& Drazen, J. C. (2007). The rate of metabolism in marine animals: environmental constraints, ecological demands and energetic opportunities. Philosophical Transactions of the Royal Society B: Biological Sciences, 362 , 2061-2078. doi:10.1098/rstb.2007.2101

Shillinger, G. L., Palacios, D. M., Bailey, H., Bograd, S. J., Swithenbank, A. M., Gaspar, P., . . Block, B. A. (2008). Persistent leatherback turtle migrations present opportunities for conservation.PLoS Biology, 6 (7), e171. doi:10.1371/journal.pbio.0060171

Shine, R. (1989). Ecological causes for the evolution of sexual dimorphism: a review of the evidence. The Quarterly Review of Biology, 64 (4), 419-461. doi:10.1086/416458

Shine, R. (1990). Proximate Determinants of Sexual Differences in Adult Body Size. The American Naturalist, 135 (2), 278-283. doi:10.1086/285043

Stamps, J., \& Krishnan, V. V. (1997). Sexual bimaturation and sexual size dimorphism in animals with asymptotic growth after maturity.Evolutionary Ecology, 11 (1), 21-39. doi:10.1023/A:1018479312191

Stamps, J. A. (2008). Sexual size dimorphism in species with asymptotic growth after maturity. Biological Journal of the Linnean Society, 50 (2), 123-145. doi:10.1111/j.1095-8312.1993.tb00921.x

Tilley, S. G. (1980). Life histories and comparative demography of two salamander populations. Copeia, 1980 (4), 806-821. doi:10.2307/1444460

Vogel, S. (1994). Life in Moving Fluids: The Physical Biology of Flow (2nd ed.). Princeton, NJ: Princeton University Press.

Walker, J. A. (2002). Functional morphology and virtual models: physical constraints on the design of oscillating wings, fins, legs, and feet at intermediate Reynolds Numbers. Integrative and Comparative Biology, 42 (2), 232-242. doi:10.1093/icb/42.2.232

Walker, J. A., \& Westneat, M. W. (2000). Mechanical performance of aquatic rowing and flying. Proceedings of the Royal Society B: Biological Sciences, 267 (1455), 1875-1881. doi:10.1098/rspb.2000.1224 
Webb, P. W. (1988). Simple physical principles and vertebrate aquatic locomotion. American Zoologist, 28 (2), 709-725. doi:10.1093/icb/28.2.709

Webb, P. W., \& De Buffrénil, V. (1990). Locomotion in the biology of large aquatic vertebrates. Transactions of the American Fisheries Society, 119 (4), 629-641. doi:doi:10.1577/15488659(1990) $119<0629:$ LITBOL $>2.3$. CO;2

Wieland, G. R. (1896). Archelon ischyros; a new gigantic cryptodire testudinate from the Fort Pierre Cretaceous of South Dakota.Series 4 Vol. 2 (12), 399-412. doi:10.2475/ajs.s4-2.12.399

Williams Terrie, M. (1999). The evolution of cost efficient swimming in marine mammals: limits to energetic optimization. Philosophical Transactions of the Royal Society of London. Series B: Biological Sciences, 354 (1380), 193-201. doi:10.1098/rstb.1999.0371

Wyneken, J. (1997). Sea turtle locomotion: mechanics, behavior, and energetics. In P. L. Lutz \& J. A. Musick (Eds.), The biology of sea turtles . Boca Raton, FL: CRC Press.

Table 1. Analyses of Variance (ANOVAs) modelling the degree of difference in body size between males and females in non-marine versus marine turtles. (a) Analysis of mean body size between males and females (b) Analysis of $\mathrm{SDI}_{\mathrm{LGF}}$ values.

\begin{tabular}{|c|c|c|c|c|}
\hline $\begin{array}{l}\text { Source of } \\
\text { variation }\end{array}$ & DF & type III SS & $F$-ratio & prob $>F$ \\
\hline $\begin{array}{l}\text { (a) Mean body } \\
\text { size MODEL- } \\
\text { adjusted } \\
\mathrm{R}^{2}=0.932099 \\
\text { Effects }\end{array}$ & 3 & 45163.097 & 426.5480 & $<0.0001$ \\
\hline $\begin{array}{l}\text { Female Carapace } \\
\text { Length }\end{array}$ & 1 & 13054.492 & 369.8839 & $<0.0001$ \\
\hline Habitat Type & 1 & 29.788 & 0.8440 & 0.3607 \\
\hline $\begin{array}{l}\text { Habitat Type } \times \\
\text { Female Carapace } \\
\text { Length }\end{array}$ & 1 & 226.311 & 6.4123 & 0.0131 \\
\hline $\begin{array}{l}\text { Error } \\
\text { corrected total }\end{array}$ & $\begin{array}{l}90 \\
93\end{array}$ & $\begin{array}{l}3176.414 \\
48339.511\end{array}$ & & \\
\hline $\begin{array}{l}\text { (b) } \text { SDI }_{\mathbf{L G F}} \\
\text { MODEL- adjusted } \\
\mathrm{R}^{2}=0.034656 \\
\text { Effects }\end{array}$ & 1 & 0.6204 & 4.3387 & 0.04 \\
\hline $\begin{array}{l}\text { Habitat Type } \\
\text { Error } \\
\text { corrected total }\end{array}$ & $\begin{array}{l}1 \\
92 \\
93\end{array}$ & $\begin{array}{l}0.6204 \\
13.1547 \\
13.7751\end{array}$ & 4.3387 & 0.04 \\
\hline
\end{tabular}

Figure Legends

Figure 1. Sex-specific body size data for seven species of marine turtles based on a new, comprehensive literature review (Supplementary Table 2). A. Male versus female carapace length for 36 populations of all seven species of marine turtles: green (green cross:Chelonia mydas), loggerhead (dark grey circle: Caretta caretta ), Kemp's ridley (red diamond: Lepidochelys kempii), olive ridley (red square: Lepidochelys olivacea 
), hawksbill (orange inverted triangle: Eretmochelys imbricata), flatback (black cross: Natator depressus ) and leatherback (blue triangle:Dermochelys coriacea). The red line is the 1:1 line, representing the null hypothesis of no SSD. The blue line is the regression (male CL $=0.38804+0.9611$ (female CL); adj $\mathrm{r}^{2}=0.96$, $\mathrm{p}<0.0001$ ), and the dotted lines are the $95 \%$ confidence intervals. See text for statistical details. B. Mean adult body size of the seven species of marine turtles with symbols as in Figure 1A. Number in parentheses is the total sample size across all studies, and error bars indicate 1 Standard Error (SE)

Figure 2. Comparisons of SSD in marine (symbols as in Figure 1) and non-marine (black open circles) aquatic turtles. A. Plot of female to male carapace length of marine versus non-marine aquatic turtles. The red line is the 1:1 line, representing the null hypothesis of no SSD. The solid lines represent the linear regressions and the dotted lines show the $95 \%$ confidence intervals. The regression for the marine turtles (blue) is: male CL $=-2.4647+1.0014$ (female CL) adj $\mathrm{r}^{2}=0.99, \mathrm{p}<0.0001$ ). The regression for the nonmarine turtles (black) is: male CL $=0.5345+0.7684$ (female CL) adj $\mathrm{r}^{2}=0.78, \mathrm{p}<0.0001$ ). See text and Table 1A for statistical details. B. Comparison of Sexual Dimorphism Index ( $\mathrm{SDI}_{\mathrm{LGF}}$ ) values for marine versus non-marine aquatic turtles (symbols as Fig. 1, Fig. 2A). The vertical red line represents the null hypothesis of no sexual dimorphism $\left(\mathrm{SDI}_{\mathrm{LGF}}=0\right)$. See text and Table $1 \mathrm{~B}$ for statistical details.

Data Accessibilty Statement

Three supplementary tables and a general description of the data mining process are included as Appendix/Electronic Supplementary Materials.

The datasets supporting this article are available in the appendix/ supplementary material.

\section{COMPETING INTERESTS STATEMENT}

The authors declare no competing interests.

\section{AUTHORS' CONTRIBUTIONS}

CF designed the study, carried out the field work, collected primary data and mined data, carried out the statistical analyses, and co-drafted the manuscript; JB participated in the design of the study, participated in data analysis and co-drafted the manuscript; PTP participated in the design of the study and critically revised the manuscript;

All authors gave final approval for publication and agree to be held accountable for the work performed therein.

\section{ACKNOWLEDGMENTS}

For help collecting the morphometric data on olive ridley turtles in Costa Rica, we thank our research assistants. The morphometric measurements were performed under research permits \#ACG-PI-034-2015, \#ACT-OR-DR-050-15, \#ACT-OR-DR-074-16, and \#ACT-OR-DR-109-16 issued by the Costa Rican government (SINAC/MINAE) and sample collection was performed in accordance with the approved guidelines of the Animal Care and Use Committee of Texas A\&M University, USA (\#IACUC 2015-0157). This work was in part supported by a Texas Sea Grant Grants-in-Aid of Graduate Research Award, and a George Bush Library Foundation Travel Grant. 

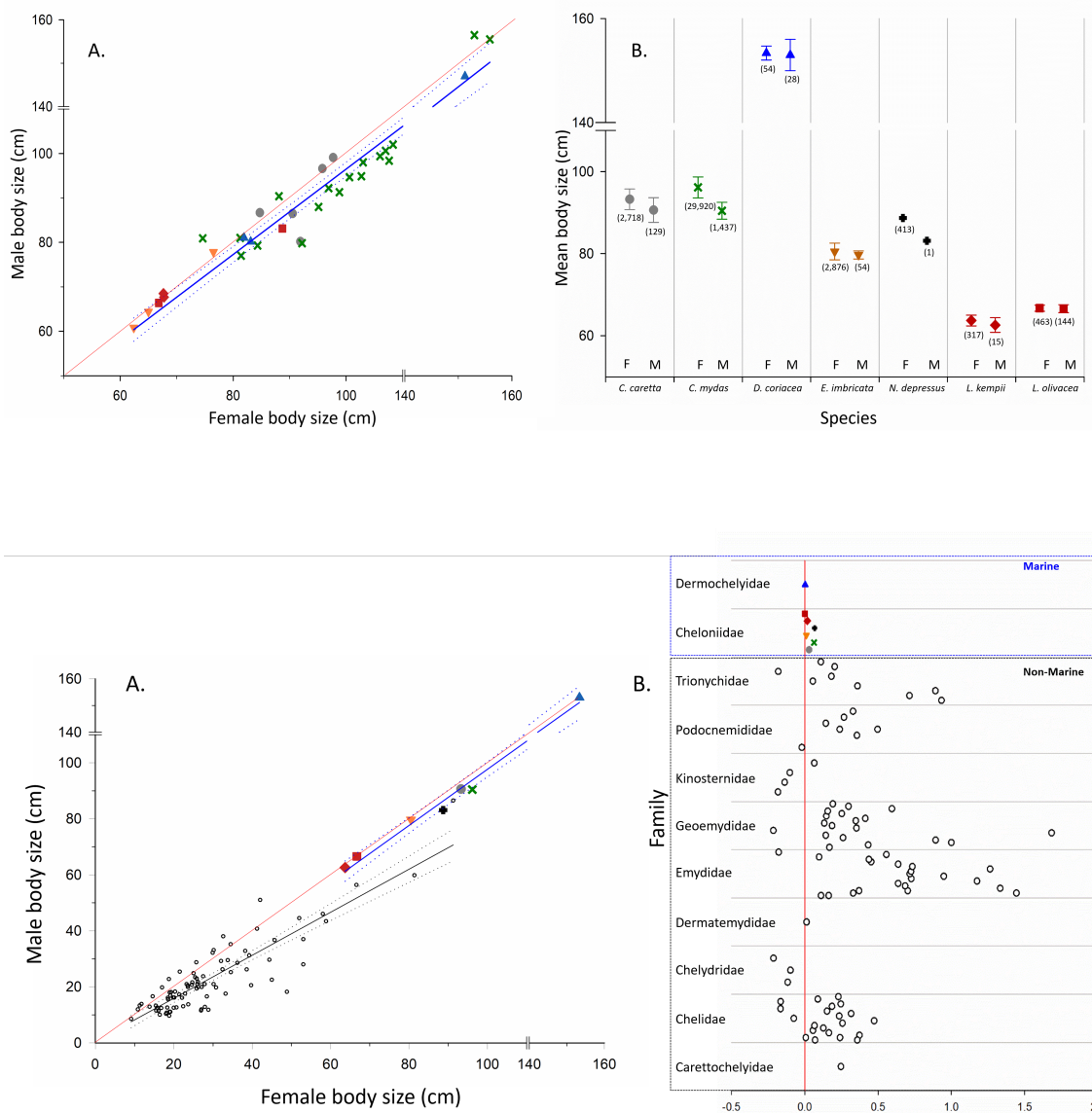

B.

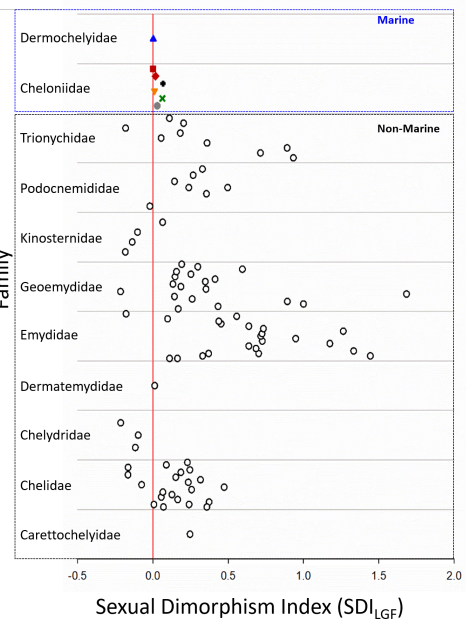

